\title{
The influences of social agents in completing a STEM degree: an examination of female graduates of selective science high schools
}

\author{
Linlin Luo ${ }^{1^{*}}\left(\mathbb{0}\right.$, Heidrun Stoeger ${ }^{1}$ (i) and Rena F. Subotnik ${ }^{2}$ (D)
}

\begin{abstract}
Background: Women are underrepresented in science, technology, engineering, and mathematics (STEM) professions. Even the most promising female students' interest in STEM subjects often decreases during secondary school. Using the framework of the Social Cognitive Career Theory, the present study examined the influences of social agents in female students' persistence in STEM. Specifically, the present study used a retrospective survey investigating the influence of parental education, teachers as mentors, and peer belonging for female students' attainment of an undergraduate degree in a STEM field for a special population - female graduates of selective science high schools $(n=1425)$. Furthermore, the study examined the influences of these social-agent variables on female students'STEM choices when mediated by high school research experiences. Finally, the present study also explored the influences of these social-agent variables on female students when it came to choosing math-intensive STEM fields $(n=723)$.

Results: Findings showed that parental educational level and having STEM teachers as mentors are positively related to female students' later attainment of a STEM degree. In addition to the direct relationship, parental educational level and having STEM teachers as mentors are also positively related to female students' high school research participation, which is associated with a greater likelihood of their completing a STEM degree. Female students' sense of belonging to a peer group did not correlate with their attainment of a STEM degree. When it came to choosing mathintensive STEM fields, a higher sense of peer belonging was negatively associated with obtaining a math-intensive STEM degree.

Conclusions: Parental education and having STEM teachers as mentors play an important role for female students' persistence in STEM and obtaining a STEM undergraduate degree for female students in selective science high schools. However, among the female students who graduated with a STEM degree, it is less clear whether socialagent variables influenced their math-intensive vs. less-math-intensive choices. Educational implications for promoting female students'STEM interests and careers in STEM fields are provided.
\end{abstract}

Keywords: Female students, Selective science high schools, Social agents, STEM majors

\footnotetext{
*Correspondence: linlin.luo@ur.de

${ }^{1}$ Chair for School Research, School Development, and Evaluation, Faculty

of Human Sciences, University of Regensburg, Regensburg, Germany

Full list of author information is available at the end of the article
}

\begin{abstract}
Introduction
Despite continuous efforts, women remain underrepresented in science, technology, engineering, and mathematics (STEM) professions, especially in math-intensive STEM fields, such as mathematics, physics, and computer science (Wang \& Degol, 2017; Wegemer \& Eccles, 2019). Selective science high schools were created to promote advanced science education and to stimulate a pipeline of future STEM professionals (Thomas \& Williams, 2009),
\end{abstract}


given that the decision to pursue a STEM-related degree or career often takes place mainly during secondary education (Maltese \& Tai, 2011; Wang, 2013). Research shows that female students' interest in STEM subjects decreases during adolescence (Blickenstaff, 2005; Frenzel et al., 2010; Rice et al., 2013). Therefore, selective science high schools, by providing high-quality STEM teaching and a supportive STEM environment, may especially benefit female students' retention in STEM fields. Although a higher percentage of female students from selective science high schools majored in STEM in college, compared to national figures (46\% vs. 36\%) (Subotnik et al., 2013; U.S. Department of Education, NCES, 2020), fewer female graduates of selective science high schools completed majors in STEM-related fields in college compared to their male counterparts (Subotnik et al., 2013). In other words, women's lower participation rate in STEM fields exists even in this highly selected group of selective science high school graduates.

The reason for this gender gap may lie in the influence of social agents. Previous research showed that parents with higher educational level tend to exert more positive influence on STEM learning (e.g., Sonnert, 2009; Spera et al., 2009). Supportive STEM teachers in high school and positive peer influence in STEM learning also contribute to persistence in STEM (e.g., Blickenstaff, 2005; Cheryan et al., 2011). However, girls tend to receive less support from parents, teachers, and peers than boys to pursue a STEM career (e.g., Fouad \& Santana, 2017; Nürnberger et al., 2016; Stoeger et al., 2016), even when they demonstrate comparable individual abilities and STEM-related interest in STEM as boys (Simpkins et al., 2006). Numerous studies revealed that parents and teachers hold less favorable beliefs about girls' math and science abilities than boys', perceive math and science as less important subjects for girls, and expect a lower performance of girls in these subjects than of boys (Gunderson et al., 2012; Simon et al., 2017). Other studies suggested that because parents, teachers, and peers tend to view STEM-related jobs as predominantly male, they might be less likely to encourage girls to pursue STEM (e.g., Bissell-Havran \& Loken, 2009; Ceci et al., 2009; Kelly, 2016; van den Hurk et al., 2019).

Although in recent years, the participation rate of women in STEM areas such as biology and medical sciences (U.S. Department of Education, 2020, NCES) have increased, women continue to be underrepresented in the most mathematically intensive STEM fields (Eccles \& Wang, 2016; Wang \& Degol, 2017; Wegemer \& Eccles, 2019). Therefore, there is a keen interest to reverse that trend (e.g., Diekman et al., 2019; Heilbronner, 2013; Tyler-Wood et al., 2018). According to Ceci et al. (2009), math-intensive fields refer to the fields "that are typically heavily involved with advanced mathematics" (p. 219) and include mathematics and statistics, computer and information sciences, engineering, and physical and technological sciences. The latest statistics on earned bachelor's degrees in 2018-2019 show that women were awarded $42 \%$ of degrees in mathematics and statistics, $21 \%$ of degrees in computer and information sciences, $23 \%$ of degrees in engineering, $21 \%$ of degrees in the physics, $38 \%$ of degrees in earth sciences, and 51\% of degrees in chemistry (National Science Foundation, NCSES, 2021; U.S. Department of Education, NCES, 2020). Studies explored possible cognitive, motivational, and sociocultural factors that might be related to the issue (see Wang \& Degol, 2017 for a review), but to our best knowledge, no empirical study has investigated the roles of social agents for female students' completing a math-intensive STEM major. Given that parents, teachers, and peers play a role in girls' decision for studying STEM in general (Fouad \& Santana, 2017; Nürnberger et al., 2016), we would expect that they might play a similar or even more important role in girls' decision for studying math-intensive STEM subjects.

The present study investigates the influences of social agents-parents, teachers, and peers-for female students' completing a STEM undergraduate degree in general and in math-intensive fields. In this study, we operationalize parental influence by parental educational level, teacher influence by having STEM teachers as mentors during high school, and peer influence by peer group belonging in high school. We used data from a survey that was designed to investigate the high school experiences of graduates of selective science high schools. The survey was administered 4-6 years after the respondents graduated from high school. Therefore, most of the respondents already had completed their undergraduate studies when they completed the survey.

\section{Literature review}

\section{Influences of social agents on general STEM retention}

To have a broad view on the influences of social agents for choosing STEM majors, we employed Social Cognitive Career Theory (SCCT; Lent et al., 1994) as a theoretical framework. Derived from Bandura's (1977) Social Cognitive Theory, the SCCT incorporates a range of social cognitive variables (e.g., interests, values, environmental support) to explain interest development and career choices. The theory posits that parents, teachers, and peers exert strong influences on interest development, which in turn, influences self-efficacy, outcome expectancy, and eventual career choice. For example, Nugent et al. (2015) tested a model using the SCCT framework and found that youth's background (including family, teachers, and peers) influenced their academic interests, 
which influenced their career outcome expectancy and career orientation. Similarly, empirical studies employed the SCCT as a framework for examining female students' STEM choices (e.g., Navarro et al., 2007; Turner et al., 2019), demonstrating that supports from parents, teachers, and peers and learning experiences in high school are related to female students' mathematics and science selfefficacy and outcome expectancy, and consequently, their eventual STEM career choices.

For the purpose of the present study, we employed the SCCT framework to examine (general and math-intense) STEM choices of female graduates of selective science high school. Specifically, we focused on the influences of social agents and chose three variables reflecting the influences of parents, teachers, and peers: parental educational level, STEM teacher as mentor, and peer group belonging. These variables have been found to influence STEM persistence and career choices in various studies (e.g., George-Jackson, 2014; Räty \& Kärkkäinen, 2011; Sonnert, 2009). In the following section, we review the literature on each variable regarding its influence on choosing STEM majors.

\section{Parental educational level}

Parents as a primary social agent influence their children's STEM choices. Studies show that parents with higher educational level exert more influences on their child's STEM career aspirations (Sonnert, 2009; Spera et al., 2009). For example, Sonnert (2009) examined a sample of 803 American scientists who were awarded prestigious postdoctoral fellowships from the National Science Foundation, National Research Council, etc. and found that parents with a higher educational level were more likelihood to be mentioned as a career influencer by their scientist child.

Parental educational level influences their children's career choices in that parents with higher educational level tend to value science learning (Almarode et al., 2018) and are more likely to provide their children with developmentally appropriate STEM learning activities (Dabney et al., 2016). Furthermore, parents with higher educational levels tend to set high expectations for their children's STEM achievements (Simpkins et al., 2006). Parents' expectancies are associated with students taking more advanced mathematics and physics courses in school (Harackiewicz et al., 2012; Rozek et al., 2015), an indicator of students' later choosing STEM as a career (Card \& Payne, 2020). Indeed, parental educational level correlates positively with students' STEM interests, activities, and achievement, which all relate to later STEM major and career choices (e.g., George-Jackson, 2014; Sahin et al., 2017). Eccles and Wang (2016) found that parental educational level positively predicted the likelihood of working in a STEM occupation vs. a nonSTEM occupation.

\section{STEM teacher as mentor}

Based on the SCCT (Lent et al., 1994), educators and mentors can pique students' interest and task values for STEM learning activities, which in turn, promotes students' self-efficacy, outcome expectancies, and eventually, career aspirations in STEM. High school mathematics and science teachers are in a unique position to serve as the first STEM mentor for the students. Bloom (1985) investigated 120 top American performers across different talent domains (e.g., math, neurology, piano, and tennis) and revealed that many highly talented mathematicians and scientists identified their school mathematics or science teacher as their first mentor.

Teachers' role as a mentor may be especially important for female students' retention in STEM. Successful female scientists and engineers acknowledge the critical role of mentors in their STEM learning and career trajectories (Mullet et al., 2017). Mentors share knowledge, serve as role models, validate female students' STEM career aspirations, and help them combat the stereotypical view of some STEM careers (e.g., engineering, physics, and computer science) being masculine professions (Pfund et al., 2016). Therefore, STEM teachers may play a vital role as an important and influential mentor for female students as they begin to explore career options and make choices that will shape their future career during high school (Blickenstaff, 2005).

\section{Peer group belonging}

The SCCT (Lent et al., 1994) posits that peers can influence STEM interest and perceived task values, which are indicators for career aspirations in STEM. Peer influence becomes increasingly relevant to students' value formation and choice making during secondary school (van den Hurk et al., 2019). For female students, peers might play an even more important role when it comes to choosing STEM subjects. Because there are stereotypes about STEM such as STEM is unfeminine (Dasgupta \& Asgari, 2004; Miller et al., 2015) and STEM is for "geeks" (Cheryan et al., 2011, 2013), female students who want to belong may not want to show interest or competence in STEM (Blackburn, 2017; Rueger et al., 2010). In contrast, social belonging can be a buffering mechanism for female students who experience negative gender bias in STEM (Cheryan et al., 2011; Robnett, 2016).

\section{High school research participation}

In addition to the direct influences, social agents may have indirect effects on STEM choices via intermediary variables. In particular, we know that social agents 
can influence students' STEM learning activities such as participation in authentic research experiences (e.g., Dabney et al., 2016; Ro et al., 2021), which in turn, influence students' career aspirations in STEM (see Sadler et al., 2010 for a review). In terms of parental influences, studies show that higher parental educational level predicted undergraduate research participation (Andriole et al., 2015; Ro et al., 2021). Although to our knowledge, there is no empirical study examining the link between parental educational level and high school research participation, we know that students with highly educated parents participated in more STEM activities during secondary school (Dabney et al., 2016; Simpkins et al., 2006), which could include participating in high school research. In addition, students who had their STEM teachers as mentors likely had more guidance toward high school research opportunities, because authentic research conducted by high school students requires mentor supervision, often outside of school (Sadler et al., 2010). Peers exert a strong influence on female students' STEM decisions (Dasgupta \& Stout, 2014; Riegle-Crumb et al., 2006), most particularly, with regard to positive research experiences (Love et al., 2007), and peer belonging increases perceived value of STEM activities for female students (van den Hurk et al., 2019). Furthermore, research shows that participation in an authentic (as opposed to a traditional school-based laboratory) research experience increases the likelihood of majoring in STEM fields in college (Sadler et al., 2010; Sahin, 2015; Salto et al., 2014). Therefore, parents, teachers, and peers may influence female students' STEM choices via their influence on high school research participation. We hypothesize that high school research participation mediates the influences of social agents on female students' choices of a STEM major in college.

\section{Influences of social agents on math-intensive STEM retention}

Nearly all research on the influence of social agents was done in STEM fields in general. Studies that differentiate between math-intense and less-math-intense fields mostly focused on individual factors, such as absolute math abilities (see Wang and Degol, 2017 for a review), relative cognitive strengths (Breda \& Napp, 2019; Wang et al., 2013), interest and perceived usefulness (MusuGillette et al., 2015), and beliefs about raw talent in mathintensive fields (Deiglmayr et al., 2019; Leslie et al., 2015). A few studies could give an idea about the potential role of social agents on math-intensive STEM choices show that parents and teachers underestimate girls' mathematics ability relative to boys' even when boys and girls have similar mathematics grades (Bleeker \& Jacobs, 2004; Lubinski et al., 2014). They often attribute girls' successes in math to effort and failures in mathematics to lack of ability, whereas for boys, the opposite attributions are believed to be true (Jacobs et al., 2005; Tiedemann, 2000). These gender-related stereotypes and biases introduced by the parents and teachers may dampen girls' career aspirations in math-intensive STEM fields. Furthermore, women have indicated preferences for working with other people (Su et al., 2009) and tend to choose careers, where they can help others and benefit society (Freund et al., 2012). Women are more likely to perceive mathintensive STEM careers as solitary in nature and, therefore, are more likely to opt for other domains (Diekman et al., 2015; McCabe et al., 2019). Parents with higher educational level and STEM teachers may be able to provide more accurate information about math-intensive STEM careers. However, to get a better understanding of the influence of parents and teachers on choices of math-intense and less-math-intense fields, more research is needed. In addition, to our knowledge, no study has examined peer influence on female students' math-intensive STEM choices. Therefore, we explore the influence of parents, teachers, and peers on female students' choices of math-intensive STEM fields in the present study.

\section{Selective science high schools}

Female graduates of selective science high schools form a selective group of girls, because unlike many peers whose STEM interest often trail off before high school (Frenzel et al., 2010; Rice et al., 2013), they demonstrated high STEM competence and interest when they enrolled (Subotnik et al., 2013). Although female students make up $53 \%$ of the student body of selective schools in the U.S., fewer than half of the female graduates (46\%) eventually attained a STEM degree in college (Subotnik et al., 2019).

In addition to a wide range of elective courses in STEM subjects usually not available at most high schools, a signature component of the selective schools is to offer authentic research experiences to those students who wish to spend the necessary time and effort. Typically, students will be matched with local scientists and spend time afterschool and/or in the summers, usually in the last year or two of secondary school. The selective schools are more likely than other schools to create accommodations for this time. Female students who participated in authentic high school experiences were 1.95 more likely to complete a STEM university degree compared to females who did not (Subotnik et al., 2019). Knowing that parents, teachers, and peers often play important roles in STEM retention in the general female student population, we wanted to explore whether they might have an influence on female students' attainment of a STEM degree in this special population. In addition to their direct influence, we were also interested 
in the possible indirect influence of these social agents on female students' later STEM choices via high school research participation, as such research opportunities were more readily organized with outside institutions by selective science high schools (Almarode et al., 2018; Thomas \& Williams, 2009). This seems especially important, because high school research participation was found to be related to completing a STEM degree in college (e.g., Almarode et al., 2014; Subotnik et al., 2019).

\section{The present study}

The purpose of the present study is to examine the influence of parents, teachers, and peers on choosing to complete an undergraduate STEM major by female students from selective science high schools. Most previous studies examined students' choices of STEM in general. By now, we know that even if female students choose a STEM major in their undergraduate studies, they are less likely to choose math-intensive subjects (e.g., Wang \& Degol, 2017). Latest statistics on earned bachelor's degrees show that women were awarded $63 \%$ of degrees in the biological and biomedical sciences, but a lot fewer in most of the math-intensive fields-about $20 \%$ of degrees in engineering and computer and information sciences, $40 \%$ of degrees in mathematical and statistics, $21 \%$ of degrees in physics, $38 \%$ of degrees in earth sciences, and $51 \%$ of degrees in chemistry (National Science Foundation, NCSES, 2021; U.S. Department of Education, NCES, 2020).

Thus, we investigate retrospectively whether three important groups of social agents (parents, teachers, and peers) affected female students' attainment of an undergraduate STEM degree, both generally and when it comes to math-intensive STEM degrees. We operationalized parental influence by parental educational level, teacher influence by asking graduates of the selective schools whether the STEM teacher acted as mentor during high school, and peer influence by asking about participants' peer group belonging during their time in a selective science high school. Moreover, we test the indirect effects of these social-agent variables on female students' attainment of a STEM degree via high school research participation. We sought to answer the following four research questions:

For female graduates of the selective science high schools:

1. What is the relationship between each social-agent variable and attaining an undergraduate STEM degree?

2. Does high school research participation mediate the effect of social-agent variables on attaining an undergraduate STEM degree?
Furthermore, for female graduates who actually attained a STEM degree:

3. What is the relationship between each social-agent variable and attaining a math-intensive STEM degree?

4. Does high school research participation mediate the effect of social-agent variables on attaining a mathintensive STEM degree?

To answer these research questions, we proposed hypotheses as follows:

1. Direct effects: The social-agent variables (i.e., parental education, STEM teacher as mentor, and peer belonging) have positive effects on high school research participation and on attaining an undergraduate STEM degree.

2. Indirect effects: The social-agent variables positively influence attaining an undergraduate STEM degree mediated by high school research participation.

These hypotheses were also tested for attaining a mathintensive STEM degree.

\section{Method}

\section{Sample and target groups}

The present study employs data from an NSF sponsored survey on graduates of selective science high schools (Subotnik et al., 2013; NSF 0815421). Previous studies using the data set examined various potential factors (e.g., parental education, early interest, research opportunities in high school) contributing to STEM choices for both male and female students (e.g., Subotnik et al., 2013). However, female students are less likely to study a STEM subject, especially a math-intensive STEM subject in college than male students (Blickenstaff, 2005), even from selective high-school environments. Therefore, the present study seeks to identify factors that might help retain high-school female student interest in STEM careers. Given the focus of the study is on female students, we selected only female participants of the survey for the analyses. At the time of the survey (4-6 years after high school graduation), most of the respondents had already completed their undergraduate studies. Among the survey respondents, $51.2 \%$ were female $(n=1797)$.

\section{Research design}

The data used in this study were collected as part of a retrospective survey study funded by the National Science Foundation (NSF DRL 0815421) investigating the high school experiences of students graduating from selective science high schools. The survey was conducted using email solicitations of a sample of selective high school 


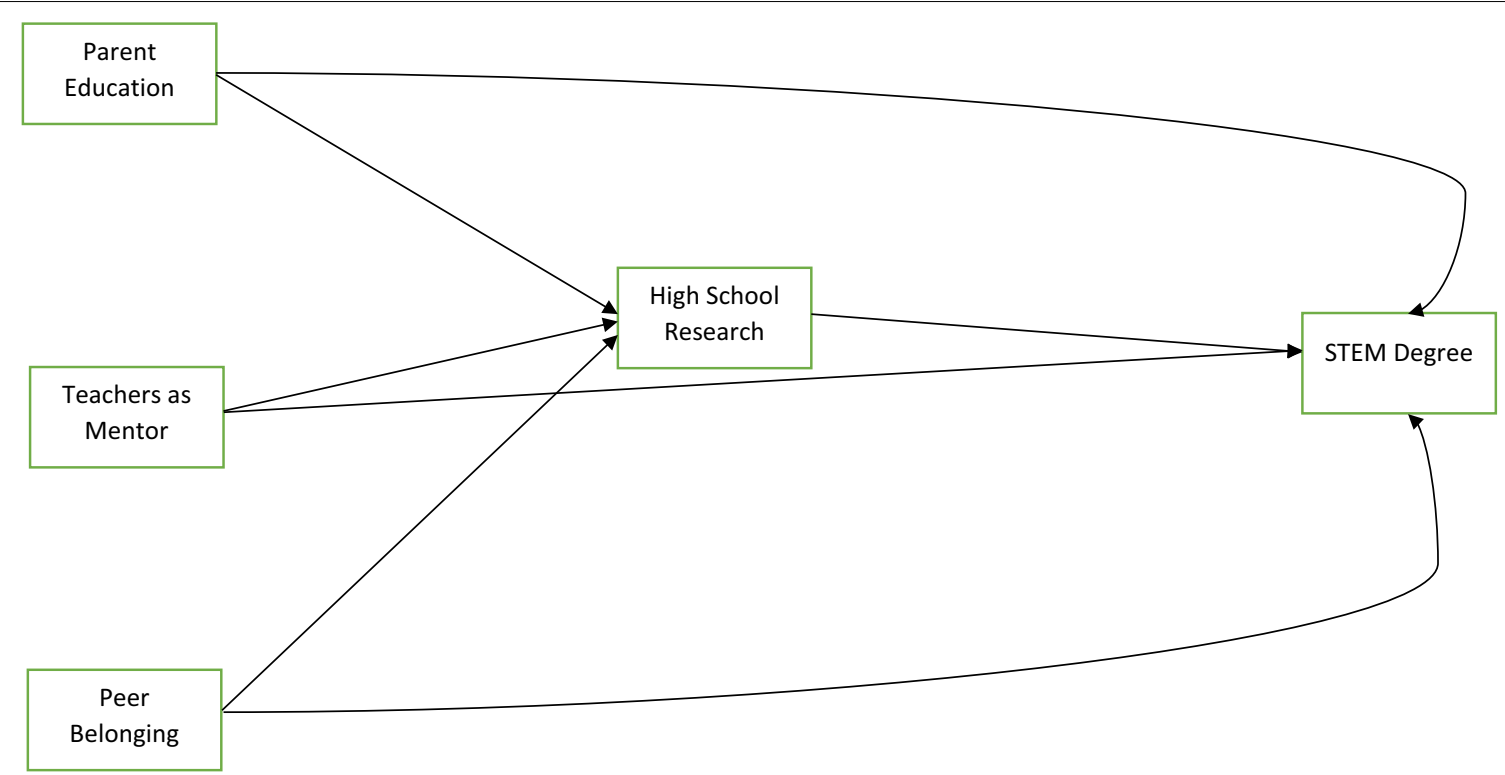

Fig. 1 Tested full path model for female students attaining a STEM degree

graduates. Contact information for the selective high school alumni was obtained through a combination of school records and alumni association lists. The survey collected respondents' demographic and background information and asked about their high school experiences such as their high school curriculum and coursework and their personal motivation in high school such as their initial interest and change of interest. The survey also included items about university majors or concentrations, high school and university research experiences, and mentors and mentoring. The survey was developed and reviewed by content experts (talent development researchers, STEM educators, and policy makers) to ensure its content validity, meaning that the items assessed the intended aspects of students' experience in the selective high schools. Previous studies using the data set for all students (both male and female students) have shown predictive validity of the survey items (e.g., Subotnik et al., 2013, 2019).

Previous studies using this data set explored personal motivational factors (e.g., early interest, change of interest) and other aspects of their high school experiences (e.g., Almarode et al., 2018; Subotnik et al., 2013, 2019). The present study focuses on the influences of social agents on female students' (general and math-intensive) STEM choices. Under the SCCT framework, we employed a path model to specify the influences three groups of social agents (parents, teachers, and peers) as well as participation in high school research have on earning a STEM degree (see Fig. 1). We chose to use a path model, because it allows us to see the total effect, direct effect, and indirect effect via a mediator.

\section{Independent variables \\ Parental educational level}

Respondents were asked: Regarding your parent or guardian with the highest level of education, what level of education did he or she complete? The options were "below high school," "high school," "baccalaureate degree," "master's degree," or "doctorate degree." Additional categories of "some college" and "other" were excluded $(n=112)$ because of the wide and undefined context of those degrees in the U.S. that might include medical assistant to cosmetology to traditional academic coursework.

\section{STEM teacher as mentor}

Respondents were asked: "Who served as a mentor to you in high school?" This variable was derived from respondents' answer to one of the options: "STEM teacher." Respondents answered either "yes" or "no." This option was chosen, because it reflects teachers' influence on students, which relates to participation in a research project. The full list of 16 mentor options (e.g., university professors, ${ }^{1}$ alumni) is provided in Additional file 1 : Online Appendix A.

\footnotetext{
${ }^{1}$ Respondents reported whether they had a university professor as a mentor in high school.
} 


\section{Peer group belonging}

The variable was derived from the question: "How would you rate your feelings of belonging within your high school peer group?" Respondents were to indicate on a 5-point Likert scale from "very weak" to "very strong."

\section{High school research participation}

The variable was derived from the question: "Did you participate in or perform original scientific research in an active research laboratory while in high school?" Respondents answered either "yes" or "no."

\section{Dependent variables STEM major}

The first path analysis focuses on STEM vs. non-STEM majors. Those respondents who reported an undergraduate major in the Biological Sciences, Chemistry, Engineering, Mathematics/Statistics, Physics, Behavioral Sciences, Computer Science, and/or Environmental Science were labeled as having earned a STEM degree. Those respondents who reported an undergraduate major in any other areas were labeled as having earned a non-STEM major. If respondents selected at least one STEM major, they were coded as 1 . If respondents did not select any STEM major, they were coded as 0 .

\section{Math-intensive STEM major}

The second path analysis focuses on math-intensive vs. less math-intensive STEM majors. Female respondents who reported having earned a STEM-related major were further categorized into having earned a math-intensive or less math-intensive STEM major. Respondents who reported an undergraduate major in Chemistry, Engineering, Mathematics/Statistics, Physics, and/or Computer Science were labeled as having earned a mathintensive STEM degree. ${ }^{2}$ Respondents who reported an undergraduate major in Biological Sciences, Behavioral Sciences, and/or Environmental Science were labeled as having earned a less math-intensive STEM major.

\section{Data analyses}

To examine the direct and indirect influences of social agents on female students' later attainment of an undergraduate STEM degree, we specified a path model, as depicted in Fig. 1. Path analyses, using the Mplus 8.0 software (Muthén \& Muthén, 1998-2017), were conducted to test the model for female graduates' completing an undergraduate degree in STEM vs. non-STEM majors and for completing a math-intensive vs. less

\footnotetext{
${ }^{2}$ In the present study, including versus not including chemistry as a mathintensive STEM field changed the results of Analysis 2. Please see Additional file 2: Online Appendix B for a more detailed explanation.
}

math-intensive STEM degree. Our sample size $(n=1685)$ was sufficient to meet the 20:1 ratio of sample size to the number of estimated paths to ensure reliable results (Petraitis et al., 1996).

\section{Results}

\section{Analysis 1: attaining a STEM degree}

The sample size for the model was 1,685. Missing data were missing completely at random, thus, were handled using listwise deletion (Zhang \& Wang, 2013). The final sample size for Analysis 1 was 1425. Descriptive statistics for measured variables are displayed in Table 1. Because the dependent variable is binary (attaining a STEM degree vs. a non-STEM degree), the hypothesized path model was fit using probit regression with the weighted least squares means and variance adjusted (WLSMV) estimation.

The hypothesized path model is just-identified with zero degrees of freedom; therefore, the model fit cannot be assessed in this case. The proportion of total variation of attaining a STEM degree explained by the model $\left(R^{2}\right)$ was 0.145 , which is considered medium (Cohen, 1988). Standardized path coefficients are reported in Table 2. Standardized path coefficients are marked above each path in Fig. 2. The size of the path coefficients shows the relative strength of the relationships between parent, teacher, and peer influences and female students' attainment of a STEM degree.

Among the social agents' variables for female students attaining an undergraduate STEM degree, the strongest influence was STEM teachers. Having STEM teachers as mentors in high school was associated with increased probability of female students attaining an undergraduate STEM degree. Parents' educational level was also positively correlated with the likelihood of female students attaining a STEM degree. Peer group belonging was not a significant variable. In addition, research participation in high school was a significant predictor for female students later attaining a STEM degree.

Furthermore, high school research experience mediated parents' and teachers' influences on female students' attainment of a STEM degree. Parental educational level and having STEM teachers as mentors predicted female students' research participation in high school, which in turn increased the likelihood of female students' attaining an undergraduate STEM degree. Specifically, there was a positive indirect effect of parental educational level on STEM choices via high school research participation $(\beta=0.021, p=0.006)$. Having STEM teachers as mentors also indirectly effected attaining a STEM degree through high school research $(\beta=0.081, p=0.001)$. 
Table 1 Descriptive statistics for measured variables in analysis 1

\begin{tabular}{|c|c|c|}
\hline Categorical variables & Frequency & Percent \\
\hline \multicolumn{3}{|l|}{ Parental education level } \\
\hline Below high school & 38 & 2.7 \\
\hline High school & 217 & 15.2 \\
\hline Baccalaureate degree & 365 & 25.6 \\
\hline Master's degree & 432 & 30.3 \\
\hline Doctorate degree & 373 & 26.2 \\
\hline \multicolumn{3}{|l|}{ STEM teacher as mentor } \\
\hline Yes & 695 & 48.8 \\
\hline No & 730 & 51.2 \\
\hline \multicolumn{3}{|l|}{ Participating in research } \\
\hline Yes & 625 & 43.9 \\
\hline No & 800 & 56.1 \\
\hline \multicolumn{3}{|l|}{ STEM major } \\
\hline Yes & 723 & 50.7 \\
\hline No & 702 & 49.3 \\
\hline Ordinal variables & Mean & Standard deviation \\
\hline Peer belonging & 3.99 & 1.072 \\
\hline
\end{tabular}

Table 2 Standardized path coefficients for the full path models

\begin{tabular}{|c|c|c|c|c|}
\hline & \multicolumn{2}{|c|}{ Model 1 (STEM vs. non-STEM) } & \multicolumn{2}{|c|}{$\begin{array}{l}\text { Model } 2 \text { (math-intensive vs. less } \\
\text { math-intensive) }\end{array}$} \\
\hline & $\beta(S E)$ & $p$ & $\beta(S E)$ & $p$ \\
\hline \multicolumn{5}{|l|}{ Research participation ON } \\
\hline Parental educational level & $0.127(0.033)$ & $<0.0001$ & $0.129(0.045)$ & 0.004 \\
\hline STEM teacher as mentor & $0.226(0.031)$ & $<0.0001$ & $0.130(0.045)$ & 0.004 \\
\hline Peer belonging & $0.015(0.032)$ & 0.649 & $0.061(0.046)$ & 0.183 \\
\hline \multicolumn{5}{|l|}{ STEM major ON } \\
\hline Parental educational level & $0.113(0.032)$ & $<0.0001$ & $0.022(0.047)$ & 0.642 \\
\hline STEM teacher as mentor & $0.270(0.031)$ & $<0.0001$ & $0.054(0.048)$ & 0.254 \\
\hline Peer belonging & $-0.050(0.032)$ & 0.119 & $-0.114(0.048)$ & 0.017 \\
\hline Research participation & $0.166(0.041)$ & $<0.0001$ & $-0.076(0.060)$ & 0.204 \\
\hline
\end{tabular}

\section{Analysis 2: attaining a math-intensive STEM degree}

Of the female students who reported having earned an undergraduate degree in a STEM field, we further divided them into "math-intensive" and "less math-intensive" STEM fields. Therefore, Analysis 2 used a subgroup of Analysis 1 (only the female respondents who earned a STEM degree, $n=807)$. Missing data were handled using listwise deletion (Zhang \& Wang, 2013). The final sample size for Analysis 2 was 723. We were interested in whether the social agents directly or indirectly influenced female students' math-intensive STEM choices. Descriptive statistics for measured variables in Analysis 2 are displayed in Table 3.
Standardized path coefficients are reported on the right side in Table 2. However, none of the social-agent or intermediary variables predicted female students' attainment of a math-intensive STEM degree. Only peers had an influence on STEM female students when it came to completing a math-intensive STEM or less math-intensive STEM degree $(\beta=-0.114, p=0.017)$. A higher sense of peer belonging was negatively associated with attaining a math-intensive STEM degree. Furthermore, two paths from the social agents to the intermediary variable were significant. First, higher parental educational level increased the likelihood 


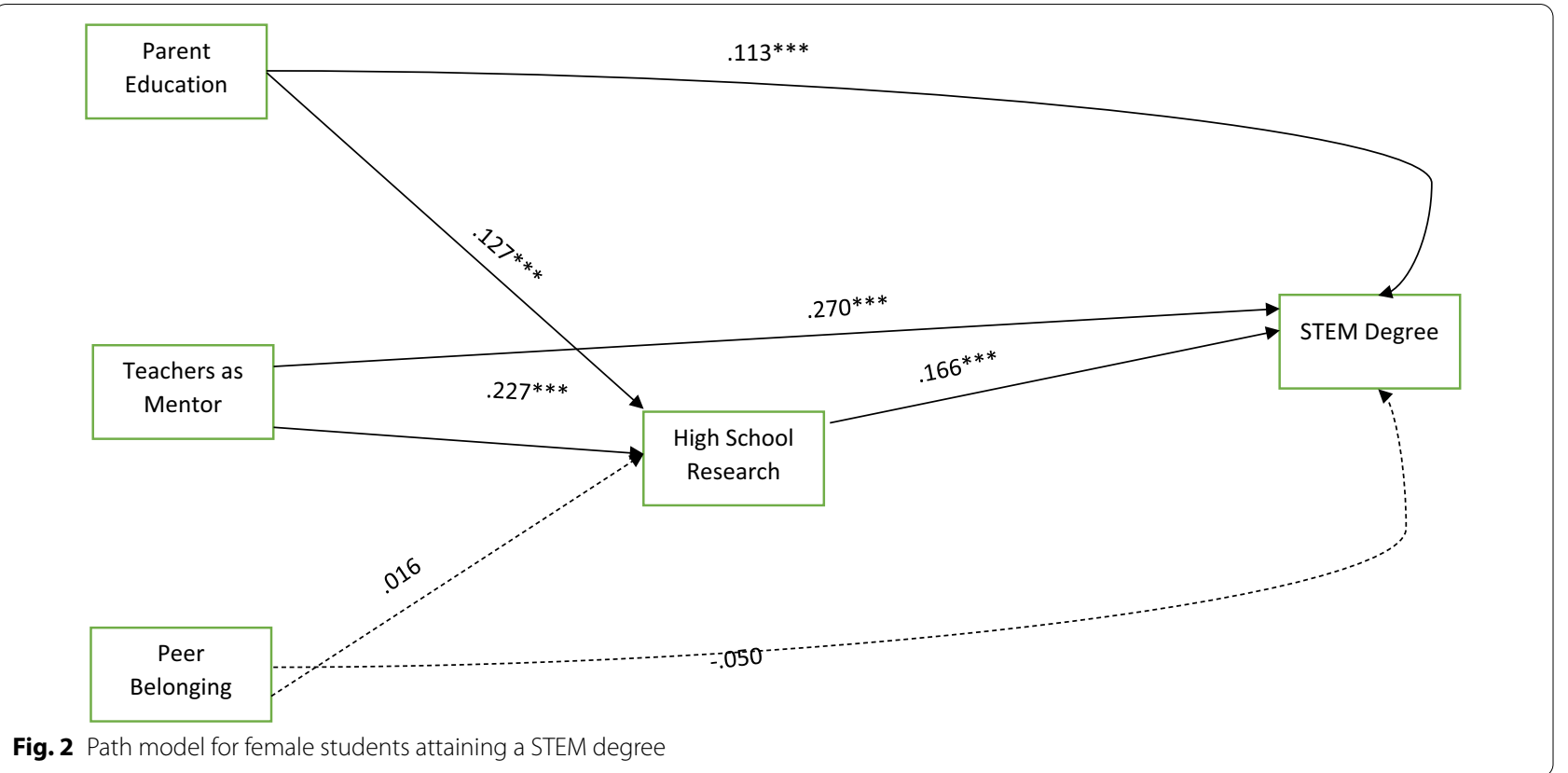

Table 3 Descriptive statistics for measured variables in analysis 2

\begin{tabular}{|c|c|c|}
\hline Categorical variables & Frequency & Percent \\
\hline \multicolumn{3}{|l|}{ Parental education level } \\
\hline Below high school & 13 & 1.8 \\
\hline High school & 89 & 12.3 \\
\hline Baccalaureate degree & 165 & 22.8 \\
\hline Master's degree & 248 & 34.3 \\
\hline Doctorate degree & 208 & 28.8 \\
\hline \multicolumn{3}{|l|}{ STEM teacher as mentor } \\
\hline Yes & 445 & 61.5 \\
\hline No & 278 & 38.5 \\
\hline \multicolumn{3}{|l|}{ Participating in research } \\
\hline Yes & 373 & 51.6 \\
\hline No & 350 & 48.4 \\
\hline \multicolumn{3}{|l|}{ STEM major } \\
\hline Math-intensive & 429 & 59.3 \\
\hline Less math-intensive & 294 & 40.7 \\
\hline Ordinal variables & Mean & Standard deviation \\
\hline Peer belonging & 3.97 & 1.092 \\
\hline
\end{tabular}

of female students participating in research in high school $(\beta=0.129, p=0.004)$. Furthermore, having STEM teachers as mentors increased the likelihood of female students participating in research in high school $(\beta=0.130, p=0.004)$. However, research participation in high school did not influence obtaining a mathintensive or less math-intensive STEM degree.

\section{Discussion}

The present study investigates the influences of parents, teachers, and peers on female graduates of selective science high schools when it comes to completing a STEM degree or not in college. Using the SCCT framework, we hypothesized that parents, teachers, and peers, as the primary social agents would influence female students' learning activities, namely, their research participation in 
high school, which would in turn, influence female students' later attainment of a STEM degree in college.

\section{STEM vs. non-STEM choices}

The first path model explored the factors contributing to completing a STEM vs. non-STEM major in college. Hypotheses were partially upheld. Regarding the direct effects hypothesis: Parental educational level and STEM teachers as mentors were indeed positively correlated with female students' attaining an undergraduate STEM degree, but a sense of belonging to a peer group did not associate with female students' STEM choices in our study. Furthermore, research participation in high school was a significant predictor for attaining an undergraduate degree in STEM. Regarding the indirect effects hypothesis: Parental educational level and STEM teachers as mentors were positively related to attaining an undergraduate STEM degree through high school research participation, but a sense of belonging to a peer group did not.

\section{Parents}

Consistent with previous research findings (George-Jackson, 2014; Sahin et al., 2017), higher parental educational level was associated with a higher likelihood of female students earning a STEM degree for the special population-female graduates from selective science schools. Even in a STEM-focused and nurturing environment, parental educational level was influential for female students' later attainment of a STEM degree. This is perhaps because highly educated parents (regardless of whether they work in a STEM field or not) tend to provide more educational resources for their children's STEM learning, including encouraging them to apply and attend a selective school, and model positive attitudes towards STEM as suggested in previous studies (Chen, 2013; Dabney et al., 2016; Simpkins et al., 2006). However, the present study cannot reveal why female students of parents with a higher educational level are more likely to obtain a STEM degree than female students of parents with a lower educational level. Therefore, future studies should take a closer look at the exact mechanisms behind these relations. For example, parents with higher educational levels might show stronger social support which correlates with self-efficacy and outcome expectancies (e.g., Navarro et al., 2007; Turner et al., 2019).

Our path model also confirmed an indirect parental effect on female students' attainment of an undergraduate STEM degree via high school research participation. Previous studies found that higher parental educational level predicted research participation during undergraduate studies (Andriole et al., 2015; Ro et al., 2021). Our study provided evidence that parental educational level also predicted female students' research participation during high school. Female students' research participation then increased the likelihood of them later completing a STEM degree in college. Therefore, according to the SCCT, parental influence as a primary source of social influences contributed to children's learning behaviors in school (i.e., research participation), which in turn, influenced students' college major choices. Although higher parental educational level had both direct and indirect positive effects on completing a STEM degree, the direct effect was larger than the indirect effect. Given that parental educational level is a chance factor for students, special attention needs to be given to the female students with lower parental educational level, even for a special population of high achieving and highly motivated students who already made it into selective science high schools.

\section{Teachers}

Having STEM teachers as mentors was the strongest predictor among the three social-agent variables. This finding was consistent with some other studies (e.g., Nugent et al., 2015; Rice et al., 2013) that included all three types of social agents (i.e., teachers, parents, and peers) in a SCCT model. Previous studies measured teacher support using items such as "my science teacher cares how we feel;" "my math teacher expects me to do well in math" (Rice et al., 2013, p. 1033). The present study examined teacher support by asking the students whether they had their STEM teachers as mentors in high school. STEM teachers as mentors could provide female students with a better understanding of the nature of STEM occupations and various STEM career options to help correct common views of STEM careers being isolated and less directly relevant to society (Wang \& Degol, 2017). Moreover, they might have served as role models for females who aspired to have a STEM career. Having a mentor who can model what it is like to be comfortable and knowledgeable in STEM can help shape female students' positive attitudes toward STEM careers and form a STEM identity (Stout et al., 2011). Young et al. (2013) found that university female students enrolled in chemistry and engineering courses were more interested in a science career when they viewed their course instructors as role models.

Furthermore, the mediation analysis revealed that having STEM teachers as mentors increased the probability of female students' completion of a STEM degree via research participation. High school STEM teachers are in a unique position to encourage students to participate in scientific research, especially in the context of selective science high school, where such research opportunities were more readily organized with outside institutions 
(Almarode et al., 2018; Thomas \& Williams, 2009). Our path model confirmed that having STEM teachers as mentors increased female students' research participation in high school. The present study also confirmed that research experienced during high school increased the probability of female students' attainment of an undergraduate STEM degree, which is consistent with previous research findings (e.g., Sadler et al., 2010; Sahin et al., 2015). Finally, the larger direct effect of having STEM teachers as mentor on female students' STEM choices compared to the indirect effect via high school research participation indicate that perhaps the psychosocial support and role modeling effect are more profound than the instructional benefits of having STEM teachers as mentor.

\section{Peers}

Unexpectedly, peer group belonging did not predict female graduates of selective science schools attaining an undergraduate STEM degree in the present study. This was inconsistent with previous SCCT studies that showed peer support positively influenced female students' self-efficacy and outcome expectations in math and science in high school (Nugent et al., 2015; Rice et al., 2013; Turner et al., 2019). This might be a result of the unique academic environment of selective science high schools. Most students enrolled in selective science high schools probably have positive attitudes towards STEM; therefore, the variation of different peer groups' influences on STEM might be smaller compared to other schools. In other words, in average schools, there are some students who love STEM, but there are also some who are aversive to STEM learning. Therefore, a large variation of peer group influence on STEM choices may exist in average schools, and female students belonging to different peer groups may be affected differently. However, in selective science high school, because most students like and are proficient in STEM subjects, the peer group a student belonged to might not have a big influence on students' STEM choices. In addition, we cannot be sure that a sense of belonging to a peer group necessarily reflects a belonging to a STEM-focused peer group. Previous studies used measures that were more directly linked to peer support in mathematics and science, such as rating the magnitude of peer support for pursuing specific STEM careers (Rice et al., 2013; Turner et al., 2019) or assessing peers' interest and achievement in math and science (Frenzel et al., 2010; Nugent et al., 2015).

\section{Math-intensive vs. less math-intensive choices}

The second path model explored the influences of social agents on female students' choice of a math-intensive or less math-intensive STEM major. According to the comprehensive review by Wang and Degol (2017) on factors contributing to women's underrepresentation in math-intensive STEM fields, sociocultural factors such as gender-related stereotypes and biases against female in math-intensive fields may explain the low participation rates of females in math-intensive STEM fields. However, little is known about the influence of social agents (parents, teachers, peers) on female students' math-intensive vs. less math-intensive STEM choices. Based on existing studies with the general female student population that social agents influence their general major and career choices in STEM (independent of the math-intensity of the chosen field; Anaya et al., 2017; Cheng et al., 2019; Cheryan et al., 2011; Navarro et al., 2007; Oguzoglu \& Ozbeklik, 2016; Turner et al., 2019), we hypothesized that having highly educated parents, STEM teachers as mentors, and feeling a sense of belonging to a peer group might increase the likelihood of female students' pursuit of a math-intensive STEM field. However, we did not find any effects of parental educational level or having STEM teachers as mentors on choosing a math-intensive STEM field among the female students who completed a STEM degree. It appears that these two social agents' variables are especially important for female students to enter STEM fields in general, but not for whether they choose a math-intensive STEM field or not. Furthermore, a sense of peer belonging was associated with lower likelihood of choosing a math-intensive STEM field. One possible explanation of the negative association is that a sense of peer belonging might be more important for female students who were inclined to less math-intensive STEM fields, such as biological sciences and behavioral sciences. As Wang and Degol (2017) suggested, female students may choose less math-intensive STEM fields over math-intensive fields, because they think that less mathintensive STEM jobs are more people-oriented and contribute to the society more. Therefore, female students who reported a higher sense of belonging within the peer group might also be more drawn to less math-intensive fields. Future studies might employ qualitative methods to further understand the relationship between peer belonging and female students' math-intensive STEM choices. Furthermore, future studies might explore cognitive and motivational factors for female students' math-intensive STEM choices, as suggested by Wang and Degol (2017).

In summary, it seemed that for female graduates of selective science schools who completed a STEM degree, the influence of peers was negatively associated with choosing a math-intensive STEM field. The influences of parents and teachers as measured in the present study did not influence female students' math-intensive vs. less math-intensive STEM choices. 


\section{Conclusion}

The present study investigates the influences of social agents on female students' attainment of an undergraduate STEM degree in general and in math-intensive STEM fields. The present study has three new perspectives. First, it focuses on a special population-female graduates from selective science high schools. These female students attended selective science high schools and responded to the survey after they graduated from college. Even though previous studies showed that parents, teachers, and peers played important roles when it comes to female students' STEM career choices in the general population (e.g., Nugent et al., 2015; Rueger et al., 2010), little is known as to whether the results hold for female students in a selective environment.

Second, the present study not only examined the direct influences of social agents on female students' attainment of a STEM degree, but it also examined the indirect influences via participation in research during high school. Previous research shows that social agents often play a role in female students' research participation (e.g., Ro et al., 2021; van den Hurk et al., 2019). Furthermore, research participation in high school is associated with female students' STEM career aspirations and choices (e.g., Niepel et al., 2019; Sadler et al., 2010). Therefore, including it as a mediator helps to explain mechanisms by which social agents influence female students' STEM choices in this special population.

Finally, the present study not only examined the influence of social agents (and research participation) on female students' choices of STEM majors in general but also on their choice of completing math-intensive STEM university majors. This is important as we know that even if female students choose a STEM field to study, they are less likely to choose math-intensive subjects (Diekman et al., 2019; Tyler-Wood et al., 2018). Although we only found a negative association between the influence of peers and female students' choices of math-intensive STEM majors, our study was a first attempt to seek understanding of the influence of social agents on this kind of choice. In future research, it would be interesting to investigate whether our results only hold for the special population, females from selective science high schools, or whether similar results can be found for females from high schools without a specialization in science.

\section{Limitations and future studies}

The present study used a retrospective survey design that asked college graduates to recall their experiences in selective science high schools. Although the survey included a wide range of variables, it was not specifically designed to examine the influences of social agents. Therefore, our analyses were somewhat limited to variables available in the survey. For instance, we used parental educational level as a proxy of parental influences. Even though studies show that parents with higher educational level exert more influences on their child's STEM career aspiration (Sonnert, 2009; Spera et al., 2009), a more ideal way of measuring parental influences would be directly asking the perceived support from parents in pursuing STEM. Future studies can examine the influences of social agents by directly asking respondents about perceived parent, teacher, and peer support in STEM learning and their influences on STEM motivation, as used in some studies (e.g., Robnett, 2013; Vekiri \& Chronaki, 2008). Furthermore, we only had one item for each type of social agent's influence. For example, the question about the parental educational level used in the survey did not differentiate mother's and father's educational level, yet studies often revealed differential effects of mother's and father's influences (e.g., Turner et al., 2019). Therefore, future studies should measure maternal and paternal educational level and influences separately. Similarly, we only had one item to measure the sense of belonging within a peer group, which was not ideal, as many established and validated measures use multiple items to measure peer belonging and support (e.g., Nugent et al., 2015; Rice et al., 2013; Turner et al., 2019). Moreover, in the framework of the current study, it was not possible to determine the causal effect of having STEM teachers as mentors on female students' STEM choices via random assignment. In our study, about $80 \%$ of female students selected their STEM teacher as a mentor, and the rest of students were either assigned a mentor by the school or selected by their mentors. ${ }^{3}$ In addition, there was no difference concerning the methods of mentor assignment between female students who later graduated with a STEM degree or nonSTEM degree, as well as between female graduates with a math-intensive or less math-intensive degree. Still, future research should continue to explore STEM mentorship in schools, such as how different mentor assignment methods (e.g., student choosing mentor, mentor selecting student) might influence female students' STEM choices. Even with these methodological limitations, we argue that the present data provided a rare opportunity to explore potential social influences on the attainment of (math-intensive) STEM university majors in a special

\footnotetext{
${ }^{3}$ The survey included a separate question: How did you come to have a high school mentor? We examined the response for this question among those who reported having STEM teachers as mentors and found no difference between STEM majors versus non-STEM majors, math-intensive versus less mathintensive female graduates. The comparison tables are provided in Additional file 3: Online Appendix C.
} 
group of participants: females from selective science high schools. The initial findings of this exploratory study have value for practice and policy for retaining female students in STEM and provide fodder for future studies.

Another limitation of our study is a possible recall bias due to employing a retrospective survey (Vermunt, 2020). Female students who earned a STEM degree might have recalled their selective science high school experiences more favorably than those who earned a non-STEM degree. Although, as shown in the comparisons, such a bias was not evident, future studies could employ a longitudinal design to collect students' data in high school, and then ask them several years later about their majors and career choices, and whether these are STEM-related. Although the retrospective survey methodology has its weaknesses, we also feel that it provided a necessary perspective to examine the relationships of the influence of social agents for female students at the time of their participation in a selective science high school and their later STEM choices when they had already completed their high school and undergraduate studies. As the first study that explored and reported associations for female students from selective science high schools and mathintensive STEM choices, our findings may be used as a springboard for more examinations of this special female student population and their math-intensive STEM choices. For example, among the math-intensive STEM fields examined, women were awarded $51 \%$ of degrees in chemistry (National Science Foundation, NCSES, 2021), making chemistry the most gender-balanced math-intensive STEM field. Therefore, future studies should explore the field of chemistry with respect to its success in the inclusion and retention of women and provide valuable lessons for the other female-underrepresented mathintensive STEM fields (Cheryan et al., 2016).

Future research on the influence of social agents on (math-intensive) STEM-choices can plan and implement a longitudinal study (e.g., data collection at start of high school, high school graduation, and college graduation) and include multiple-item measures for socialagent variables. In addition, the present study focused on females graduated from selective high school; therefore, the results may not be generalizable to all female students. Future research should compare female students from selective and non-selective high schools to explore the mechanisms that lead to STEM choices in different contexts.

Some educational and research implications follow from the present study. First, high school STEM teachers exert strong influences on female students' STEM choices, especially when students regard them as mentors. Our data show that the most common mentors for STEM females were their STEM teachers. Therefore, teachers are in a prime position to help combat negative stereotypes. They could create classroom environments that do not treat males and females differently in terms of their STEM potential. Furthermore, they could share successful examples of female STEM professionals and their achievements especially in math-intensive STEM fields. Many stereotype-eliminating strategies by teachers have been found effective to increase female students' self-efficacy and identity in STEM (e.g., Stout et al., 2011).

STEM teachers should also encourage female students to participate in authentic scientific research in high school and mentor them through the processes of finding a place in a university or commercial laboratory, as we see that high school research participation increased the likelihood of females earning a STEM degree in college. Conducting authentic research provides a socializing experience into the STEM enterprise, demonstrating that it can be interactive and exciting. In this way, young women can more easily and accurately visualize whether this is the life they want for themselves (Eccles, 2011; Wang \& Degol, 2013).

We also found that parental educational level predicted female students' STEM choices. We acknowledge that the parental education is a chance factor. However, parents, regardless of their educational and career background, can benefit from learning and applying strategies to incorporate STEM into daily activities, encourage their children to participate in school- and communitybased STEM programs, and help combat STEM stereotypes by modelling positive attitudes towards females in STEM fields at home. Schools should give more support to parents to acquire such strategies and information, especially to parents with a lower educational level as they might not have the same knowledge and economic wherewithal to best support their children. Additional recommendations for supporting students from demographically disadvantaged families can be found in Subotnik et al. (2019).

Another supportive measure for female students, especially those without the kind of parental support available by STEM knowledgeable parents, is to provide them with other mentors, in addition to their STEM subject teachers. Research shows that female mentors and role models are especially important for female students' career aspirations in STEM (Herrmann et al., 2016; Rosenthal et al., 2013; Stout et al., 2011). Therefore, schools and STEM institutions should collaborate and provide more female students with mentors in STEM fields. However, the underrepresentation of females in STEM fields, especially in math-intensive STEM fields, results from a shortage of female mentors and role models for girls who are interested in these fields (Blickenstaff, 2005; Makarova et al., 2019). The smaller numbers of female 
math-intensive mentors exacerbates the process by which mentors for more advanced mentees are chosen by the mentors rather than paired up by teachers or other organized programs (Subotnik et al., 2021). One alternative is to take advantage of online mentoring programs for STEM students. For example, a Germany-wide online mentoring program that matches high-school girls with female STEM professionals as e-mentors, has shown effectiveness in promoting girls' STEM elective intentions, certainty about career goals and STEM activities (Stoeger et al., 2019, 2021). Another approach is to help female students attract the interest of high status female mentors by way of self-introductions, polished resumes, and interview practice (Subotnik et al., 2021).

Finally, although we sought to identify possible influences of social agents on female students' attainment of a math-intensive STEM degree, we only found a negative association between peer belonging and female students' math-intensive STEM choices. As mentioned in the discussion, we cannot tell in the present study whether the reported peer belonging reflected a belonging to a STEM-focused peer group. Therefore, we cannot be certain about the explanation of this negative relationship. Moreover, it remains unclear whether and how other social-agent influences might contribute to female students choosing a math-intensive STEM field over a less math-intensive STEM field. Future research should continue to explore potential social-agent variables, as well as other promotive factors, that support female students in general and from selective science high schools in particular to pursue a math-intensive STEM career. For example, a longitudinal study that compare girls from selective and non-selective science high schools and include different measures on social-agent and other promotive factors would be an ideal way to gain a deeper understanding of the mechanisms that lead to STEM choices in different contexts.

\section{Abbreviations}

STEM: Science, technology, engineering, and mathematics; SCCT: Social cognitive career theory; NSF: National Science Foundation.

\section{Supplementary Information}

The online version contains supplementary material available at https://doi. org/10.1186/s40594-021-00324-w.

\section{Additional file 1. Appendix A.}

Additional file 2. Appendix $B$.

Additional file 3. Appendix C.

Acknowledgements

Not applicable.

\section{Authors' contributions}

LL was a major contributor in conceptualizing the manuscript, analyzing and interpreting the data, and writing the manuscript. HS was a major contributor in conceptualizing and revising the manuscript. RFS was a major contributor by way of providing the original data set, conceptualizing and revising the manuscript. All authors read and approved the final manuscript.

\section{Funding}

Open Access funding enabled and organized by Projekt DEAL. The data set used in the present study is collected in an NSF sponsored survey (NSF 0815421).

\section{Availability of data and materials}

The data set analyzed in the present study is available from the authors upon reasonable request.

\section{Declarations}

\section{Competing interests}

The authors declare that they have no competing interests.

\section{Author details}

${ }^{1}$ Chair for School Research, School Development, and Evaluation, Faculty of Human Sciences, University of Regensburg, Regensburg, Germany. ${ }^{2}$ Center for Psychology in Schools and Education, American Psychological Association, Washington D.C., USA.

Received: 28 June 2021 Accepted: 25 December 2021

Published online: 20 January 2022

\section{References}

Almarode, J. T., Subotnik, R. F., Dabney, K. P., Crowe, E., Tai, R. H., \& Kolar, C. (2018). Parent or guardian characteristics and talented students' persistence in STEM. In Teaching gifted learners in STEM subjects (pp. 46-64). Routledge. https://doi.org/10.4324/9781315814247.

Almarode, J. T., Subotnik, R. F., Crowe, E., Tai, R. H., Lee, G. M., \& Nowlin, F. (2014). Specialized high schools and talent search programs: Incubators for adolescents with high ability in STEM disciplines. Journal of Advanced Academics, 25, 307-331. https://doi.org/10.1177/1932202X14 536566

Anaya, L., Stafford, F. P., \& Zamarro, G. (2017). Gender gaps in math performance, perceived mathematical ability and college STEM education: The role of parental occupation (SSRN Scholarly Paper ID 3068971). Social Science Research Network. https://papers.ssrn.com/abstract=3068971.

Andriole, D. A., Jeffe, D. B., \& Tai, R. H. (2015). Participation in college laboratory research apprenticeships among students considering careers in medicine. Medical Education Online, 20(1), 27231. https://doi.org/10.3402/ meo.v20.27231

Bandura, A. (1977). Self-efficacy: Toward a unifying theory of behavioral change. Psychological Review, 84(2), 191-215. https://doi.org/10.1037/ 0033-295X.84.2.191

Bissell-Havran, J. M., \& Loken, E. (2009). The role of friends in early adolescents' academic self-competence and intrinsic value for math and English. Journal of Youth and Adolescence, 38(1), 41-50. https://doi.org/10.1007/ s10964-007-9266-3

Blackburn, H. (2017). The status of women in STEM in higher education: A review of the literature 2007-2017. Science and Technology Libraries, 36(3), 235-273. https://doi.org/10.1080/0194262X.2017.1371658

Bleeker, M. M., \& Jacobs, J. E. (2004). Achievement in math and science: Do mothers' beliefs matter 12 years later? Journal of Educational Psychology, 96(1), 97-109. https://doi.org/10.1037/0022-0663.96.1.97

Blickenstaff, J. C. (2005). Women and science careers: Leaky pipeline or gender filter? Gender and Education, 17(4), 369-386. https://doi.org/10.1080/ 09540250500145072

Bloom, B. S. (1985). Generalizations about talent development. In B. S. Bloom (Ed.), Developing talent in young people (pp. 507-549). Ballantine Books.

Breda, T., \& Napp, C. (2019). Girls' comparative advantage in reading can largely explain the gender gap in math-related fields. Proceedings of the National 
Academy of Sciences, 116(31), 15435-15440. https://doi.org/10.1073/pnas. 1905779116

Card, D., \& Payne, A. A. (2020). High school choices and the gender gap in STEM. Economic Inquiry, 59, 9-28. https://doi.org/10.1111/ecin.12934

Ceci, S. J., Williams, W. M., \& Barnett, S. M. (2009). Women's underrepresentation in science: Sociocultural and biological considerations. Psychological Bulletin, 135(2), 218-261. https://doi.org/10.1037/a0014412

Chen, X. (2013). STEM attrition: College students' paths into and out of STEM fields (Statistical Analysis Report NCES 2014-001; p. 104). National Center for Education Statistics, Institute of Education Sciences, U.S. Department of Education. https://nces.ed.gov/pubs2014/2014001 rev.pdf.

Cheng, A., Kopotic, K., \& Zamarro, G. (2019). Parental occupational choice and children's entry into a STEM field (SSRN Scholarly Paper ID 3457307). Socia Science Research Network. https://papers.ssrn.com/abstract=3457307.

Cheryan, S., Plaut, V. C., Handron, C., \& Hudson, L. (2013). The stereotypical computer scientist: Gendered media representations as a barrier to inclusion for women. Sex Roles, 69(1-2), 58-71. https://doi.org/10.1007/ s11199-013-0296-x

Cheryan, S., Siy, J. O., Vichayapai, M., Drury, B. J., \& Kim, S. (2011). Do female and male role models who embody STEM stereotypes hinder women's anticipated success in STEM? Social Psychological and Personality Science, 2(6), 656-664. https://doi.org/10.1177/1948550611405218

Cheryan, S., Ziegler, S. A., Montoya, A. K., \& Jiang, L. (2016). Why are some STEM fields more gender balanced than others? Psychological Bulletin, 143(1), 1-35. https://doi.org/10.1037/bul0000052

Cohen, J. (1988). Statistical power analysis for the behavioural sciences (2nd ed.). Lawrence Erlbaum Associates.

Dabney, K. P., Tai, R. H., \& Scott, M. R. (2016). Informal science: Family education, experiences, and initial interest in science. International Journal of Science Education, Part B, 6(3), 263-282. https://doi.org/10.1080/21548455.2015. 1058990

Dasgupta, N., \& Asgari, S. (2004). Seeing is believing: Exposure to counterstereotypic women leaders and its effect on the malleability of automatic gender stereotyping. Journal of Experimental Social Psychology, 40(5), 642-658. https://doi.org/10.1016/j.jesp.2004.02.003

Dasgupta, N., \& Stout, J. G. (2014). Girls and women in science, technology, engineering, and mathematics: STEMing the tide and broadening participation in STEM careers. Policy Insights from the Behavioral and Brain Sciences, 1(1), 21-29. https://doi.org/10.1177/2372732214549471

Deiglmayr, A., Stern, E., \& Schubert, R. (2019). Beliefs in "brilliance" and belonging uncertainty in male and female STEM students. Frontiers in Psychology, 10, 1114. https://doi.org/10.3389/fpsyg.2019.01114

Diekman, A. B., Clark, E. K., \& Belanger, A. L. (2019). Finding common ground: Synthesizing divergent theoretical views to promote women's STEM pursuits. Social Issues and Policy Review, 13(1), 182-210. https://doi.org/10. 1111/sipr.12052

Diekman, A. B., Weisgram, E. S., \& Belanger, A. L. (2015). New routes to recruiting and retaining women in STEM: Policy implications of a communal goal congruity perspective. Social Issues and Policy Review, 9(1), 52-88. https://doi.org/10.1111/sipr.12010

Eccles, J. S. (2011). Understanding educational and occupational choices. Journal of Social Issues, 67(3), 644-648. https://doi.org/10.1111/j.15404560.2011.01718.x

Eccles, J. S., \& Wang, M.-T. (2016). What motivates females and males to pursue careers in mathematics and science? International Journal of Behavioral Development, 40(2), 100-106. https://doi.org/10.1177/0165025415616201

Fouad, N. A., \& Santana, M. C. (2017). SCCT and underrepresented populations in STEM fields: Moving the needle. Journal of Career Assessment, 25(1), 24-39. https://doi.org/10.1177/1069072716658324

Frenzel, A. C., Goetz, T., Pekrun, R., \& Watt, H. M. G. (2010). Development of mathematics interest in adolescence: Influences of gender, family, and school context. Journal of Research on Adolescence, 20(2), 507-537. https://doi.org/10.1111/j.1532-7795.2010.00645.x

Freund, A. M., Weiss, D., \&Wiese, B. S. (2012). Graduating from high school: the role of gender-related attitude, attributes, and motives for a central transition in late adolescence. Switzerland: Department of Psychology, University of Zurich. https://doi.org/10.1080/17405629.2013.772508. Unpublished manuscript.

George-Jackson, C. E. (2014). Undergraduate women's persistence in the sciences. NASPA Journal About Women in Higher Education, 7(1). https://doi. org/10.1515/njawhe-2014-0006.
Gunderson, E. A., Ramirez, G., Levine, S. C., \& Beilock, S. L. (2012). The role of parents and teachers in the development of gender-related math attitudes. Sex Roles, 66(3), 153-166. https://doi.org/10.1007/s11199-011-9996-2

Harackiewicz, J. M., Rozek, C. S., Hulleman, C. S., \& Hyde, J. S. (2012). Helping parents to motivate adolescents in mathematics and science: An experimental test of a utility-value intervention. Psychological Science, 23(8), 899-906. https://doi.org/10.1177/0956797611435530

Heilbronner, N. N. (2013). The STEM pathway for women: What has changed? Gifted Child Quarterly, 57(1), 39-55. https://doi.org/10.1177/0016986212 460085

Herrmann, S. D., Adelman, R. M., Bodford, J. E., Graudejus, O., Okun, M. A., \& Kwan, V. S. Y. (2016). The effects of a female role model on academic performance and persistence of women in STEM courses. Basic and Applied Social Psychology, 38(5), 258-268. https://doi.org/10.1080/01973 533.2016.1209757

Jacobs, J. E., Chhin, C. S., \& Shaver, K. (2005). Longitudinal links between perceptions of adolescence and the social beliefs of adolescents: Are parents' stereotypes related to beliefs held about and by their children? Journal of Youth and Adolescence, 34(2), 61-72. https://doi.org/10.1007/ s10964-005-3206-X

Kelly, A. M. (2016). Social cognitive perspective of gender disparities in undergraduate physics. Physical Review Physics Education Research, 12(2), 020116. https://doi.org/10.1103/PhysRevPhysEducRes.12.020116

Lent, R. W., Brown, S. D., \& Hackett, G. (1994). Toward a unifying social cognitive theory of career and academic interest, choice, and performance. Journal of Vocational Behavior, 45(1), 79-122. https://doi.org/10.1006/jvbe.1994. 1027

Leslie, S.-J., Cimpian, A., Meyer, M., \& Freeland, E. (2015). Expectations of brilliance underlie gender distributions across academic disciplines. Science, 347(6219), 262-265. https://doi.org/10.1126/science.1261375

Love, K. M., Bahner, A. D., Jones, L. N., \& Nilsson, J. E. (2007). An investigation of early research experience and research self-efficacy. Professional Psychology: Research and Practice, 38(3), 314-320. https://doi.org/10.1037/07357028.38.3.314

Lubinski, D., Benbow, C. P., \& Kell, H. J. (2014). Life paths and accomplishments of mathematically precocious males and females four decades later. Psychological Science, 25(12), 2217-2232. https://doi.org/10.1177/09567 97614551371

Makarova, E., Aeschlimann, B., \& Herzog, W. (2019). The gender gap in STEM fields: The impact of the gender stereotype of math and science on secondary students' career aspirations. Frontiers in Education, 4, 60. https:// doi.org/10.3389/feduc.2019.00060

Maltese, A. V., \& Tai, R. H. (2011). Pipeline persistence: Examining the association of educational experiences with earned degrees in STEM among U.S. students. Science Education, 95(5), 877-907. https://doi.org/10.1002/sce. 20441

McCabe, K. O., Lubinski, D., \& Benbow, C. P. (2019). Who shines most among the brightest?: A 25-year longitudinal study of elite STEM graduate students. Journal of Personality and Social Psychology, 119(2), 390-416. https://doi. org/10.1037/pspp0000239

Miller, D. I., Eagly, A. H., \& Linn, M. C. (2015). Women's representation in science predicts national gender-science stereotypes: Evidence from 66 nations. Journal of Educational Psychology, 107(3), 631-644. https://doi.org/10. 1037/edu0000005

Mullet, D. R., Rinn, A. N., \& Kettler, T. (2017). Catalysts of women's talent development in STEM: A systematic review. Journal of Advanced Academics, 28(4), 253-289. https://doi.org/10.1177/1932202X17735305

Musu-Gillette, L. E., Wigfield, A., Harring, J. R., \& Eccles, J. S. (2015). Trajectories of change in students'self-concepts of ability and values in math and college major choice. Educational Research and Evaluation, 21(4), 343-370. https://doi.org/10.1080/13803611.2015.1057161

Muthén, L.K., \& Muthén, B.O. (1998-2017). Mplus User's Guide. Eighth Edition. Muthén \& Muthén.

National Center for Science and Engineering Statistics, National Science Foundation (2021). Women, minorities, and persons with disabilities in science and engineering. Retrieved from https://ncses.nsf.gov/pubs/nsf21321/ report/field-of-degree-women\#earth-and-physical-sciences.

Navarro, R. L., Flores, L. Y., \& Worthington, R. L. (2007). Mexican American middle school students' goal intentions in mathematics and science: A test of social cognitive career theory. Journal of Counseling Psychology, 54(3), 320-335. https://doi.org/10.1037/0022-0167.54.3.320 
Niepel, C., Stadler, M., \& Greiff, S. (2019). Seeing is believing: Gender diversity in STEM is related to mathematics self-concept. Journal of Educational Psychology, 111(6), 1119-1130. https://doi.org/10.1037/edu0000340

Nugent, G., Barker, B., Welch, G., Grandgenett, N., Wu, C., \& Nelson, C. (2015). A model of factors contributing to STEM learning and career orientation. International Journal of Science Education, 37(7), 1067-1088. https://doi. org/10.1080/09500693.2015.1017863

Nürnberger, M., Nerb, J., Schmitz, F., Keller, J., \& Sütterlin, S. (2016). Implicit gender stereotypes and essentialist beliefs predict preservice teachers' tracking recommendations. The Journal of Experimental Education, 84(1), 152-174. https://doi.org/10.1080/00220973.2015.1027807

Oguzoglu, U., \& Ozbeklik, S. (2016). Like father, like daughter (unless there is a SOn): Sibling sex composition and women's STEM major choice in college (SSRN Scholarly Paper ID 2810463). Social Science Research Network. https://papers.ssrn.com/abstract=2810463.

Petraitis, P. S., Dunham, A. E., \& Niewiarowski, P. H. (1996). Inferring multiple causality: The limitations of path analysis. Functional Ecology, 10(4), 421-431. https://doi.org/10.2307/2389934

Pfund, C., Byars-Winston, A., Branchaw, J., Hurtado, S., \& Eagan, K. (2016). Defining attributes and metrics of effective research mentoring relationships. AIDS and Behavior, 20(S2), 238-248. https://doi.org/10.1007/ s10461-016-1384-z

Räty, H., \& Kärkkäinen, R. (2011). Talent or effort? Parents' explanations of their children's mathematical performance in relation to mathematical competence. Social Behavior and Personality, 39(5), 691-700. https://doi.org/10. 2224/sbp.2011.39.5.691

Rice, L., Barth, J. M., Guadagno, R. E., Smith, G. P. A., McCallum, D. M., ASERT. (2013). The role of social support in students' perceived abilities and attitudes toward math and science. Journal of Youth and Adolescence, 42(7), 1028-1040. https://doi.org/10.1007/s10964-012-9801-8

Riegle-Crumb, C., Farkas, G., \& Muller, C. (2006). The role of gender and friendship in advanced course taking. Sociology of Education, 79(3), 206-228. https://doi.org/10.1177/003804070607900302

Ro, H. K., Lee, J., Fernandez, F., \& Conrad, B. H. (2021). We don't know what they did last summer: Examining relationships among parental education, faculty interaction, and college students' post-first year summer experiences. Innovative Higher Education, 46(1), 21-39. https://doi.org/10.1007/ s10755-020-09523-9

Robnett, R. (2013). The role of peer support for girls and women in STEM: Implications for identity and anticipated retention. International Journal of Gender, Science and Technology, 5(3), 232-253.

Robnett, R. D. (2016). Gender bias in STEM fields: Variation in prevalence and links to STEM self-concept. Psychology of Women Quarterly, 40(1), 65-79. https://doi.org/10.1177/0361684315596162

Rosenthal, L., Levy, S. R., London, B., Lobel, M., \& Bazile, C. (2013). In pursuit of the MD: The impact of role models, identity compatibility, and belonging among undergraduate women. Sex Roles, 68(7-8), 464-473. https://doi. org/10.1007/s11199-012-0257-9

Rozek, C. S., Hyde, J. S., Svoboda, R. C., Hulleman, C. S., \& Harackiewicz, J. M. (2015). Gender differences in the effects of a utility-value intervention to help parents motivate adolescents in mathematics and science. Journal of Educational Psychology, 107(1), 195-206. https://doi.org/10.1037/a0036 981

Rueger, S. Y., Malecki, C. K., \& Demaray, M. K. (2010). Relationship between multiple sources of perceived social support and psychological and academic adjustment in early adolescence: Comparisons across gender. Journal of Youth and Adolescence, 39(1), 47-61. https://doi.org/10.1007/ s10964-008-9368-6

Sadler, T. D., Burgin, S., McKinney, L., \& Ponjuan, L. (2010). Learning science through research apprenticeships: A critical review of the literature. Journal of Research in Science Teaching, 47(3), 235-256. https://doi.org/10. 1002/tea.20326

Sahin, A. (2015). STEM Students on the Stage (SOS): Promoting student voice and choice in STEM education through an interdisciplinary, standardsfocused project based learning approach. Journal of STEM Education, 16(3). Retrieved from https://www.learntechlib.org/p/151970/.

Sahin, A., Ekmekci, A., \& Waxman, H. C. (2017). The relationships among high school STEM learning experiences, expectations, and mathematics and science efficacy and the likelihood of majoring in STEM in college. International Journal of Science Education, 39(11), 1549-1572. https://doi.org/ 10.1080/09500693.2017.1341067
Sahin, A., Gulacar, O., \& Stuessy, C. (2015). High school students' perceptions of the effects of international science olympiad on their STEM career aspirations and twenty-first century skill development. Research in Science Education, 45(6), 785-805. https://doi.org/10.1007/s11165-014-9439-5

Salto, L. M., Riggs, M. L., Leon, D. D. D., Casiano, C. A., \& Leon, M. D. (2014). Underrepresented minority high school and college students report STEM-pipeline sustaining gains after participating in the Loma Linda University summer health disparities research program. PLOS ONE, 9(9), e108497. https://doi.org/10.1371/journal.pone.0108497

Simon, R. M., Wagner, A., \& Killion, B. (2017). Gender and choosing a STEM major in college: Femininity, masculinity, chilly climate, and occupational values. Journal of Research in Science Teaching, 54(3), 299-323. https://doi. org/10.1002/tea.21345

Simpkins, S. D., Davis-Kean, P. E., \& Eccles, J. S. (2006). Math and science motivation: A longitudinal examination of the links between choices and beliefs. Developmental Psychology, 42(1), 70-83. https://doi.org/10.1037/00121649.42.1.70

Sonnert, G. (2009). Parents who influence their children to become scientists: Effects of gender and parental education. Social Studies of Science, 39(6), 927-941. https://doi.org/10.1177/0306312709335843

Spera, C., Wentzel, K. R., \& Matto, H. C. (2009). Parental aspirations for their children's educational attainment: Relations to ethnicity, parental education, children's academic performance, and parental perceptions of school climate. Journal of Youth and Adolescence, 38(8), 1140-1152. https://doi. org/10.1007/s10964-008-9314-7

Stoeger, H., Debatin, T., Heilemann, M., \& Ziegler, A. (2019). Online mentoring for talented girls in STEM: The role of relationship quality and changes in learning environments in explaining mentoring success. New Directions for Child and Adolescent Development, 2019(168), 75-99. https://doi.org/ 10.1002/cad.20320

Stoeger, H., Heilemann, M., Debatin, T., Hopp, M. D. S., Schirner, S., \& Ziegler, A. (2021). Nine years of online mentoring for secondary school girls in STEM: An empirical comparison of three mentoring formats. Annals of the New York Academy of Sciences, 1483(1), 153-173. https://doi.org/10.1111/nyas. 14476

Stoeger, H., Schirner, S., Laemmle, L., Obergriesser, S., Heilemann, M., \& Ziegler, A. (2016). A contextual perspective on talented female participants and their development in extracurricular STEM programs: Talented females in an extracurricular STEM program. Annals of the New York Academy of Sciences, 1377(1), 53-66. https://doi.org/10.1111/nyas.13116

Stout, J. G., Dasgupta, N., Hunsinger, M., \& McManus, M. A. (2011). STEMing the tide: Using ingroup experts to inoculate women's self-concept in science, technology, engineering, and mathematics (STEM). Journal of Personality and Social Psychology, 100(2), 255-270. https://doi.org/10.1037/a0021385

Su, R., Rounds, J., \& Armstrong, P. I. (2009). Men and things, women and people: A meta-analysis of sex differences in interests. Psychological Bulletin, 135(6), 859-884. https://doi.org/10.1037/a0017364

Subotnik, R. F., Olszewski-Kubilius, P., Khalid, M., \& Finster, H. (2021). A developmental view of mentoring talented students in academic and nonacademic domains. Annals of the New York Academy of Sciences, 1483(1), 199-207. https://doi.org/10.1111/nyas.14286

Subotnik, R. F., Stoeger, H., \& Luo, L. (2019). Exploring compensations for demographic disadvantage in science talent development. New Directions for Child and Adolescent Development, 2019(168), 101-130. https://doi.org/10. 1002/cad.20321

Subotnik, R. F., Tai, R. H., Almarode, J. T., \& Crowe, E. (2013). What are the value added contributions of selective secondary schools of mathematics, science, and technology to the preparation of scientists? Talent Development and Excellence, 5, 87-97.

Thomas, J., \& Williams, C. (2009). The history of selective STEM schools and the formation and role of the NCSSSMST. Roeper Review, 32(1), 17-24. https:// doi.org/10.1080/02783190903386561

Tiedemann, J. (2000). Parents' gender stereotypes and teachers' beliefs as predictors of children's concept of their mathematical ability in elementary school. Journal of Educational Psychology, 92(1), 144-151. https://doi.org/ 10.1037/0022-0663.92.1.144

Turner, S. L., Joeng, J. R., Sims, M. D., Dade, S. N., \& Reid, M. F. (2019). SES, gender, and STEM career interests, goals, and actions: A test of SCCT. Journal of Career Assessment, 27(1), 134-150. https://doi.org/10.1177/1069072717 748665 
Tyler-Wood, T., Johnson, K., \& Cockerham, D. (2018). Factors influencing student STEM career choices: Gender differences. Journal of Research in STEM Education, 4(2), 179-192.

U.S. Department of Education, National Center for Education Statistics (NCES). (2020). Digest of education statistics. Retrieved from https://nces.ed.gov/ programs/digest/2020menu_tables.asp.

van den Hurk, A., Meelissen, M., \& van Langen, A. (2019). Interventions in education to prevent STEM pipeline leakage. International Journal of Science Education, 41(2), 150-164. https://doi.org/10.1080/09500693.2018. 1540897

Vekiri, I., \& Chronaki, A. (2008). Gender issues in technology use: Perceived social support, computer self-efficacy and value beliefs, and computer use beyond school. Computers and Education, 51(3), 1392-1404. https:// doi.org/10.1016/j.compedu.2008.01.003

Vermunt, J. D. (2020). Surveys and retrospective self-reports to measure strategies and strategic processing. In D. L. Dinsmore, L. K. Fryer, \& M. M. Parkinson (Eds.), Handbook of strategies and strategic processing (pp. 259-274). Routledge.

Wang, M.-T., \& Degol, J. (2013). Motivational pathways to STEM career choices: Using expectancy-value perspective to understand individual and gender differences in STEM fields. Developmental Review, 33(4), 304-340. https://doi.org/10.1016/j.dr.2013.08.001

Wang, M.-T., \& Degol, J. L. (2017). Gender gap in science, technology, engineering, and mathematics (STEM): Current knowledge, implications for practice, policy, and future directions. Educational Psychology Review, 29(1), 119-140. https://doi.org/10.1007/s10648-015-9355-x

Wang, M.-T., Eccles, J. S., \& Kenny, S. (2013). Not lack of ability but more choice: Individual and gender differences in choice of careers in science, technology, engineering, and mathematics. Psychological Science, 24(5), 770-775. https://doi.org/10.1177/0956797612458937

Wang, X. (2013). Why students choose STEM majors: Motivation, high school learning, and postsecondary context of support. American Educational Research Journal, 50(5), 1081-1121. https://doi.org/10.3102/0002831213 488622

Wegemer, C. M., \& Eccles, J. S. (2019). Gendered STEM career choices: Altruistic values, beliefs, and identity. Journal of Vocational Behavior, 110, $28-42$. https://doi.org/10.1016/j.jvb.2018.10.020

Young, D. M., Rudman, L. A., Buettner, H. M., \& McLean, M. C. (2013). The influence of female role models on women's implicit science cognitions. Psychology of Women Quarterly, 37(3), 283-292. https://doi.org/10.1177/ 0361684313482109

Zhang, Z., \& Wang, L. (2013). Methods for mediation analysis with missing data. Psychometrika, 78(1), 154-184. https://doi.org/10.1007/ s11336-012-9301-5

\section{Publisher's Note}

Springer Nature remains neutral with regard to jurisdictional claims in published maps and institutional affiliations.

\section{Submit your manuscript to a SpringerOpen ${ }^{\circ}$ journal and benefit from:}

- Convenient online submission

- Rigorous peer review

- Open access: articles freely available online

- High visibility within the field

- Retaining the copyright to your article

Submit your next manuscript at $\gg$ springeropen.com 